\title{
Assessment the Effect of Pomegranate Molasses against Diazinon Toxicity in Male Rats
}

\author{
H. A. Abd Elmonem \\ Biological Application Department, Nuclear Research Center, Atomic Energy Authority, Cairo, Egypt.
}

\begin{abstract}
Diazinon (DZN) is one of the organophosphorus $(O P)$ insecticides, can affect both animals and man even after exposure to a single dose. Pomegranate molasses (PM), a concentrated pomegranate juice, may be rich in more efficient antioxidants than that found in the juice, but no research has been done on this product. Therefore, the aim of this study was to evaluate the possible protective effect of PM against single half lethal dose of DZN $(300 \mathrm{mg} / \mathrm{Kg} b \mathrm{wt})$ induced adverse effects on contents of Malondialdehyde (MAD) and reduced glutathione (GSH) in rat liver and brain tissues, haematological and some biochemical parameters. Thirty six male albino rats were divided into four groups for ten days as follows: Groupl, rats from that group were fed orally with $0.5 \mathrm{ml}$ from a corn oil (6 rats). Group (2) rats were injected orally with a single dose of LD50 of DZN (300mg/kg) (12 rats), group (3) rats were given $0.5 \mathrm{ml}$ PM plus $0.5 \mathrm{ml}$ distilled water / day for 10 days (6 rats), Group (4) animals were given the same single dose of DZN as group plus PM / day for 10 days (12 rats). The results demonstrated that treatment with DZN induced significant increase in MDA and significant decrease in GSH levels in liver and brain tissues. These changes were almost returned to normalcy in rats supplemented with $P M+D Z N$ except brain MAD still higher than control group. Red blood corpuscles (RBC) count, hemoglobin $(\mathrm{Hb})$ concentrations and hematocrit $(\mathrm{Hct})$ showed significant reduction, while the value of white blood corpuscles (WBC) count was statistically increased in rats exposed to DZN. Significant increases in the values of serum total protein (TP), globulin (Glob), total cholesterol (TC), triglyceride (TG), urea, uric acid and calcium $(\mathrm{Ca})$ were observed in DZN administrated rats compared to control group. However, PM supplementation together with DZN improved all these alterations except albumin (Alb) and TG significant increased than control group.
\end{abstract}

Key words: Diazinon, pomegranate molasses, oxidative stress, hematological, biochemical, rats

\section{Introduction}

Diazinon (DZA) is a commonly used OP pesticide. It has been used since 1956 for the control of soil insects and pests, on ornamental plants, and on fruits, vegetables and field crops. Now it is used to control flies around animal facilities, greenhouses, fairgrounds and other businesses and public places where food or animal wastes might be accumulated [1]. Due to extensive use of DZN, its residues have been detected in foodstuffs prepared for human consumption [2]. It can cause different health Problems due to the inhibition of acetylcholinesterase at nerve endings, which leads to the accumulation of acetylcholine neurotransmitter and consequently over-stimulation of muscarinic and nicotinic receptors [3]. Some reports have been published with respect to DZN and its effects on biochemical and hematological parameters of rats [4,5], and generating free radicals and altering the depressing the activities of the free radical scavenging enzymes by induce oxidative stress [6].

Pomegranate (Punica granatum L.), is a plant used in popular folkloric medicine for the treatment of various diseases [7]. It is an important source of anthocyanins, hydrolysable tannins punicalagin and punicalin [8], ellagic and gallic acids [9] and also contains vitamin C [10]. Recent studies have demonstrated its anticancer activity in several human cancers [11]. Apart from its antioxidant capacity, numerous reports have been published on the in vivo properties of pomegranates, namely on anti-atherosclerotic capacity [12], antiproliferative and pro-apoptotic activities of pomegranate tannin extract [13], anti-inflammatory activity [14].

Pomegranate molasses (PM), a concentrated pomegranate juice is widely consumed in the Middle East; it may be rich in more efficient antioxidants than that found in the juice. It is commonly used in salads and many dishes to improve the taste and aroma characteristics in Egypt, it is a concentrated product produced simply by boiling the juice with the addition of sugar and lemon juice. Researchers have been dealt with this subject are scantly. Hence, the aim of this study was to evaluate the possible ameliorative effects of PM supplementation against toxicity of a single half lethal dose (LD50 $=300 \mathrm{mg} / \mathrm{Kg} \mathrm{b}$ wt) of DZN on levels of MAD and GSH in liver and brain tissues, besides hematological and some biochemical parameters in rats. 


\section{1-Chemical}

\section{Material And Methods}

DZN was prepared by Nippo Kayaku Company, Ltd, Japan and kindly provided by Cairo Liaison office, Sumitomo Corporation (Sumitomo Shaji Kaisha, Ltd) in technical grade of 93\% and dissolved in corn oil. The DZN was introduced orally through oral tube in a dose of 300mg/kg $=$ LD50 [15].

PM was prepared of the components of that found in the super market by added sugar and lemon juice to Pomegranate juice ( 4 cup pomegranate juice $+1 / 2$ cup lemon juice $+1 / 2$ cup sugar) and boiling for 6hours.

\section{2-Experimental design}

Thirty six male albino rats, weighting about 80-90gm and obtained from the laboratory animal house of the Institute of Ophthalmology Giza, Egypt were used in the study. All animals were housed in stainless steel cages covered with wire mesh lid and allowed balanced standard diet and water ad libitum for one week for adaptation. Rats exposed to a $12 \mathrm{~h}$ light: $12 \mathrm{~h}$ dark cycle at a room temperature of $18-22^{\circ} \mathrm{C}$, and divided into four groups.

Group1 (G1): Male rats of that group were fed orally with a corn oil ( $0.5 \mathrm{ml})$ (6 rats).

Group2 (G2): Rats of that group were injected orally with a single dose of LD50 of DZN (300mg/kg) (12 rats). Group3 (G3): Animals were given $0.5 \mathrm{ml}(\mathrm{PM})$ plus $0.5 \mathrm{ml}$ distilled water / day for 10 days (6 rats).

Group4 (G4): Animals were given single dose of DZN (300mg/Kg) plus PM / day for 10 days (12 rats).

\section{3-Samples}

At the end of 10 days, the animals were sacrificed by decapitation. Liver and brain tissues from each rat were removed, washed with saline solution, tissues were homogenized in ice-cold $50 \mathrm{mM}$ sodium phosphate buffer ( $\mathrm{pH} 7.4$ ) containing $0.1 \mathrm{mM}$ ethylene diamine tetraacetic acid (EDTA) to yield $10 \%(\mathrm{~W} / \mathrm{V})$ homogenate. The homogenate was centrifuged at $10,000 \mathrm{xg}$ for $20 \mathrm{~min}$ at $4 \mathrm{C}^{\circ}$ and the resultant supernatant of the liver and brain were used for the determination of MAD, and GSH by using commercial kits purchased from Biodiagnostic reagent kits Co., Dokki, Giza, Egypt by the methods of Beutler et al. [16] and Ohkawa et al. [17] respectively. Blood sample was collected in two tubes, one with EDTA for determination of blood picture including RBCs, Hb, HCT\%, and WBCs were estimated using automatic blood cell counter ERMA PCE - 210 $\mathrm{N}$. The other tube without anticoagulant then centrifuged at 3000rpm for 15 minutes to obtain serum for TP, Alb, TC, TG, urea, uric acid, $\mathrm{Ca}, \mathrm{Mg}$ and $\mathrm{P}$, which were estimated calorimetrically using spectrophotometer (Milton Roy Spectronic 1201) using commercial kits purchased from Biodiagnostic reagent kits, Dokki, Giza, Egypt. Globulin concentration was obtained by subtracting the values of albumin from their corresponding value of total protein. The A/G ratio was calculated by dividing each albumin value by its corresponding globulin value. Serum parathyroid hormone (PTH) level was determined using radioimmunoassay kit purchased from Diagnostic Products Corporation (DPC), Los Angeles, California, USA.

\section{4-Statistical Analysis}

The obtained data were presented as means \pm SD. One-way analysis of variance (ANOVA) was carried out. The statistical comparisons among the groups were performed with Duncan's test, using a statistical package program (COSTAT). Differences among the groups were considered significant at $\mathrm{P}<0.05$.

\section{Results}

The results showed that at $24 \mathrm{hr}$ post administration of single dose of DZN, the mortality percentage was 50 corresponding to $300 \mathrm{mg} / \mathrm{Kg}$ b wt DZN, in group 2 and in group 4 half of rats died.

In this study, (table1) showed that single dose of $300 \mathrm{mg} / \mathrm{Kg}$ DZN intake led to significant decrease in GSH and increase in MAD levels in liver and brain tissues compared to control group $(\mathrm{P}<0.05)$. These changes were almost returned to normalcy in rats supplemented with PM +DZN except liver GSH decrease than control but increase than DZN group and brain MAD still higher than control group.

The results of the present study revealed significant decreases in $\mathrm{Hb}$ concentration, RBCs count and $\mathrm{HCT} \%$ and a significant increase WBC with single dose of DZN administered group compared to control. Administration of PM combined with DZN improved Hb concentration, RBCs count, HCT\% and WBC (Table 2).

Table3 showed mean values of TP, Alb, Glob, A/G ratio, TC, TG, urea and uric acid for all tested group. There were significant increases in the levels of TP and Glo at $\mathrm{P}<0.05$ in G2 compared to control group. The results revealed significant $(\mathrm{P}<0.05)$ increase in TC, TG, urea and uric acid in DZN group (G2). These alternation were almost returned to normalcy in rats supplemented with PM +DZN in G4 except Alb, A/G ratio and TG higher than control group. 
Table(1): Malondialdehyde (MAD) and reduced glutathione (GSH) in liver and brain homogenates tissues of male rats exposed to $300 \mathrm{mg} / \mathrm{Kg}$ diazinon (DZN) and/or pomegranate molasses (PM).

\begin{tabular}{|l|l|l|l|l|}
\hline \multicolumn{1}{|c|}{ Groups } & \multicolumn{1}{|c|}{$\begin{array}{c}\text { G1 } \\
\text { Parameters }\end{array}$} & $\begin{array}{c}\text { G2 } \\
(\text { Control) }\end{array}$ & $\begin{array}{c}\text { G3 } \\
(\mathbf{P M})\end{array}$ & $\begin{array}{c}\text { G4 } \\
(\mathbf{D Z N}+\mathbf{P M})\end{array}$ \\
\hline $\begin{array}{l}\text { GSH (nmol/g.tissue) } \\
\text { (Liver) }\end{array}$ & $12.19 \pm 1.76^{\mathrm{a}}$ & $2.03 \pm 1.09^{\mathrm{c}}$ & $14.24 \pm 2.7^{\mathrm{a}}$ & $6.57 \pm 1.59^{\mathrm{b}}$ \\
\cline { 2 - 5 } (Brain) & $7.39 \pm 0.91^{\mathrm{a}}$ & $5.13 \pm 1.26^{\mathrm{b}}$ & $7.55 \pm 0.55^{\mathrm{a}}$ & $6.99 \pm 0.73^{\mathrm{a}}$ \\
\hline $\begin{array}{l}\text { MAD(nmol/g.tissue) } \\
\text { (Liver) }\end{array}$ & $20.08 \pm 0.14^{\mathrm{b}}$ & $34.03 \pm 8.7^{\mathrm{a}}$ & $23.65 \pm 1.69^{\mathrm{b}}$ & $25.83 \pm 1.7^{\mathrm{b}}$ \\
\cline { 2 - 5 } (Brain) & $29.44 \pm 0.8^{\mathrm{c}}$ & $39.18 \pm 4.6^{\mathrm{a}}$ & $32.77 \pm 0.61^{\mathrm{bc}}$ & $35.94 \pm 3.15^{\mathrm{ab}}$ \\
\hline
\end{tabular}

Data represented as mean \pm SE .6rats each group Means with different superscripts in the same row re significantly different $(\mathrm{P}<0.05)$.

Table (2): Hematological parameters of male rats exposed to $300 \mathrm{mg} / \mathrm{Kg}$ diazinon (DZN) and/or pomegranate molasses (PM).

\begin{tabular}{|c|c|c|c|c|}
\hline $\begin{array}{c}\text { Groups } \\
\text { Parameters }\end{array}$ & $\begin{array}{c}\text { G1 } \\
\text { (Control) } \\
\end{array}$ & $\begin{array}{c}\text { G2 } \\
\text { (DZN) }\end{array}$ & $\begin{array}{c}\text { G3 } \\
(\mathbf{P M})\end{array}$ & $\begin{array}{c}\text { G4 } \\
(\mathrm{DZN}+\mathrm{PM})\end{array}$ \\
\hline $\mathbf{H b}(\mathrm{g} / \mathrm{dl})$ & $13.37 \pm 1.16^{\mathrm{a}}$ & $8.2 \pm 1.12^{b}$ & $13.98 \pm 2.36^{\mathrm{a}}$ & $12.28 \pm 1.15^{\mathrm{a}}$ \\
\hline RBCs $\times 10^{6} / \mathrm{mm}^{3}$ & $6.88 \pm 0.67^{\mathrm{a}}$ & $2.84 \pm 0.45^{\mathrm{b}}$ & $7.15 \pm 0.29^{\mathrm{a}}$ & $6.41 \pm 0.42^{\mathrm{a}}$ \\
\hline HCT \% & $48.4 \pm 2.89^{\mathrm{a}}$ & $22.05 \pm 5.18^{b}$ & $47.45 \pm 2.2^{\mathrm{a}}$ & $41.08 \pm 7.02^{\mathrm{a}}$ \\
\hline $\mathrm{WBCs} \times 10^{3} / \mathrm{mm}^{3}$ & $9.4 \pm 0.46^{\mathrm{b}}$ & $16.75 \pm 3.59^{\mathrm{a}}$ & $7.1 \pm 1.6^{\mathrm{b}}$ & $8.93 \pm 1.44^{b}$ \\
\hline
\end{tabular}

Data represented as mean \pm SE .6rats each group. Means with different superscripts in the same row are significantly different $(\mathrm{P}<0.05)$.

Table (3): Serum total protein (TP), albumin (Alb), globulin (Glob.), A/G ratio, total cholesterol (TC), triglyceride (TG), urea and uric acid of male rats exposed to $300 \mathrm{mg} / \mathrm{Kg}$ diazinon (DZN) and/or pomegranate molasses (PM).

\begin{tabular}{|c|c|c|c|c|}
\hline Groups & $\begin{array}{c}\text { G1 } \\
\text { Parameters }\end{array}$ & $\begin{array}{c}\text { G2 } \\
\text { (Control) }\end{array}$ & $\begin{array}{c}\text { G3 } \\
(\mathbf{P M})\end{array}$ & $\begin{array}{c}\text { G4 } \\
(\mathbf{D Z N + P M})\end{array}$ \\
\hline TP (g/dl) & $6.70 \pm 1.07^{\mathrm{b}}$ & $8.36 \pm 1.04^{\mathrm{a}}$ & $7.14 \pm 0.18^{\mathrm{b}}$ & $6.99 \pm 0.97^{\mathrm{b}}$ \\
\hline Alb (g/dl) & $3.59 \pm 0.63^{\mathrm{b}}$ & $3.86 \pm 0.16^{\mathrm{ab}}$ & $4.06 \pm 0.14^{\mathrm{ab}}$ & $4.39 \pm 0.35^{\mathrm{a}}$ \\
\hline Glo. (g/dl) & $3.12 \pm 0.66^{\mathrm{b}}$ & $4.58 \pm 0.87^{\mathrm{a}}$ & $3.07 \pm 0.04^{\mathrm{b}}$ & $2.63 \pm 0.076^{\mathrm{b}}$ \\
\hline A/G ratio & $1.18 \pm 0.22^{\mathrm{bc}}$ & $0.88 \pm 0.13^{\mathrm{c}}$ & $1.32 \pm 0.07^{\mathrm{b}}$ & $1.78 \pm 0.47^{\mathrm{a}}$ \\
\hline TC (mg/dl) & $81.53 \pm 5.2^{\mathrm{ab}}$ & $96.76 \pm 12.7^{\mathrm{a}}$ & $72.55 \pm 7.9^{\mathrm{b}}$ & $82.46 \pm 16.5^{\mathrm{ab}}$ \\
\hline TG (mg/dl) & $49.26 \pm 4.71^{\mathrm{b}}$ & $80.36 \pm 11.66^{\mathrm{a}}$ & $51.68 \pm 3.78^{\mathrm{b}}$ & $72.41 \pm 6.74^{\mathrm{a}}$ \\
\hline $\begin{array}{c}\text { Urea } \\
\text { (mg/d) }\end{array}$ & $22.62 \pm 1.12^{\mathrm{b}}$ & $30.66 \pm 1.14^{\mathrm{a}}$ & $23.41 \pm 0.88^{\mathrm{b}}$ & $23.37 \pm 1.09^{\mathrm{b}}$ \\
\hline Uric acid (mg/dl) & $3.38 \pm 0.52^{\mathrm{b}}$ & $5.0 \pm 0.82^{\mathrm{a}}$ & $3.74 \pm 0.67^{\mathrm{ab}}$ & $3.82 \pm 1.14^{\mathrm{ab}}$ \\
\hline
\end{tabular}

Data represented as mean \pm SE .6rats each group. Means with different superscripts in the same row are significantly different $(\mathrm{P}<0.05)$.

Table4 showed significant increase $(\mathrm{P}<0.05)$ in $\mathrm{Ca}$ and non-significant change in $\mathrm{Mg}, \mathrm{P}$ and $\mathrm{PTH}$ in DZN group and this increase returned to normal value by adding PM in group 4 compared to control group. On the other hand, no statistically significant differences were observed in the levels of serum biochemical parameters in rats treated with only PM 
Table (4): Serum calcium (Ca), magnesium (Mg), inorganic phosphorus (P) and parathyroid hormone (PTH) of male rats exposed to $300 \mathrm{mg} / \mathrm{Kg}$ diazinon (DZN) and/or pomegranate molasses (PM).

\begin{tabular}{|c|c|c|c|c|}
\hline Groups & $\begin{array}{c}\text { G1 } \\
(\text { Control) }\end{array}$ & $\begin{array}{c}\text { G2 } \\
\text { Parameters }\end{array}$ & $\begin{array}{c}\text { G3 } \\
(\mathbf{P M})\end{array}$ & $\begin{array}{c}\text { G4 } \\
(\mathbf{D Z N}+\mathbf{P M})\end{array}$ \\
\hline $\mathbf{C a}(\mathbf{m g} / \mathbf{d l})$ & $9.87 \pm 0.58^{\mathrm{b}}$ & $11.65 \pm 1.09^{\mathrm{a}}$ & $10.51 \pm 0.57^{\mathrm{b}}$ & $9.54 \pm 1.01^{\mathrm{b}}$ \\
\hline $\mathbf{M g}(\mathbf{m g} / \mathbf{d l})$ & $3.09 \pm 0.44^{\mathrm{a}}$ & $3.94 \pm 0.59^{\mathrm{a}}$ & $2.93 \pm 0.59^{\mathrm{a}}$ & $3.57 \pm 1.19^{\mathrm{a}}$ \\
\hline $\mathbf{P ~}(\mathbf{m g} / \mathbf{d l})$ & $5.38 \pm 0.6^{\mathrm{a}}$ & $4.62 \pm 0.22^{\mathrm{a}}$ & $4.5 \pm 0.31^{\mathrm{a}}$ & $4.74 \pm 0.19^{\mathrm{a}}$ \\
\hline $\mathbf{P T H}(\mathbf{p g} / \mathbf{m l})$ & $8.88 \pm 0.75^{\mathrm{a}}$ & $8.68 \pm 0.50^{\mathrm{a}}$ & $8.78 \pm 0.86^{\mathrm{a}}$ & $9.72 \pm 0.57^{\mathrm{a}}$ \\
\hline
\end{tabular}

Data represented as mean \pm SE .6rats each group. Means with different superscripts in the same row are significantly different $(\mathrm{P}<0.05)$.

\section{Discussion}

In this study the single dose of $300 \mathrm{mg} / \mathrm{Kg}$ DZN intake led to significant decrease in GSH and increase in MAD levels in liver and brain tissues compared to control group $(\mathrm{P}<0.05)$. This could be due to that DZN might be induce oxidative stress, leading to the generation of free radicals and an alteration in antioxidant defense system [18]. GSH is an important naturally occurring antioxidant, which prevents free radical damage and helps detoxification by conjugating with chemicals. Also, it is a principle cellular antioxidant defends and acts as an essential cofactor for antioxidant enzymes including GPX and GST [19]. MDA is considered the most commonly indicator of lipid peroxidation. Its level increases in tissues when they are exposed to oxidative stress. This result is in agreement with the study of El-Shenawy et al. [20] who demonstrated a significant increase in MAD and decrease in GSH content in liver of mice by DZN. Supplementation with antioxidants effectively suppressed the oxidative damage induced by OP pesticides [21]. Antioxidant activity of pomegranate is referred to its polyphenolic contents such as ellagic acid and ellagitannis [13], which may suggest its role as an electron donor in scavenging free radicals [22]. Significant decrease in GSH and an increase in MDA in liver and brain tissue of G2 were partially returned to the control levels by PM in G4 due to the free radical scavenging properties of the PM. These results are in agreement with Cekmen et al. [23] who observed that pomegranate extract has strong antioxidant properties against gentamicin induced nephrotoxicity, as it increased the level of GSH and decreased level of MAD in kidney cortex tissue. Mahmoud and Abdel Moneim [24], reported that $\mathrm{CCl} 4$ enhanced $\mathrm{MAD}$ generation and decreased GSH content in brain tissues of rats, administration of pomegranate juice alone decreased the levels of MAD and increased GSH content of the brain. In addition, the present investigation showed significant decrease of GSH in liver and increase of MDA in brain tissues in G4 which supplied by PM +DZN compared to control group. This may be attributed to that fresh pomegranate juice may have a more considerable amount of polyphenols than that found in PM obtained after 6 hours of heating. One can consider that high temperature should deteriorate polyphenols in PM as severe thermal treatment can alter the bioavailability of polyphenols by decreasing the absorption of active compounds, due to the formation of oxidized products [25] and also ascorbic acid present in pomegranate and lemonic juice can easily undergo thermal degradation and / or consumption in the Maillard reaction pathway [26]. In addition, PM may also contain free radicals as it contains sugar and heated at high temperatures. Namiki and Hayashi [27] observed the formation of free radicals during the early stages of the Maillard reaction was previously proposed for a glucose.alanine model system.

The present results showed that administration of single dose of $300 \mathrm{mg} / \mathrm{Kg}$ DZN caused highly decrease in RBC count, $\mathrm{Hb}$ concentration and HCT\%. This may be due to the effect of DZN on blood forming organ (bone marrow and liver), and inhibition of many steps of heme biosynthesis and increased rate of breakdown of red cells [28]. This finding is in agreement with Al- Attar and Al-Taisan [29] who noticed reduce of R.B.C., Hb and HCT\% in rats given an oral dose of $12.8 \mathrm{mg} / \mathrm{kg}$.of DZN. Shakoori et al. [30] suggested that the decrease in RBC count is either indicative of excessive damage to erythrocytes or inhibition of erythrocytes formation. Moreover, the hepatic heme biosynthesis has already been reported to be affected by insecticidal exposure, which also contributes to decreased RBC count and $\mathrm{Hb}$ concentration [31].

In the present investigation, the administration of DZN induced increases in the number of WBC. Further induction of leukocytosis is considered an immunological response to meet the adverse situation 
developed by the introduction of DZN in the blood. It may also be for the removal of the debris of tissue damaged by the DZN. Several studies showed that the treatment with different pesticides markedly stimulated the animal's defence mechanism and immune system [32, 5]. Administration of PM combined with DZN improved $\mathrm{Hb}$ concentration, RBCs number, HCT\%, and WBCs count (Table1). The improved change in haematological parameters in the group given PM as a protective substance could be due to the fact that pomegranate is an important source of iron (the building block needed to produce Haemoglobin) and phenolic compounds which have antioxidant and free radical scavenging activity [33] thus preventing the possible tissue damage caused by the DZN.

There were significant increases in the levels of TP and Glo at P $<0.05$ in G2 compared to control group. These results may be due to the liver and kidney dysfunction. These results were in full agreement with Saxena and Saxena [34] and Diab et al. [35] they reported that changes in the level of TP in rats exposed to OP pesticides reflect disorders in the synthesis and metabolism of proteins. Mousa et al. [36] they mentioned that fish under stress may mobilize protein to meet energy requirements needed to sustain increased physiological activity. These increases were almost restored to normalcy in rats supplemented with PM plus DZN (G4) compared to control group. Alb and A/G ratio showed significant increase in G4 compared to control group. This may be due to PM having less antioxidant effect due to heating as previously mentioned.

Lipids play an important role in virtually all aspects of biological processes in the body. Disturbances of their level in tissues and serum are usually associated with many abnormalities, including gallstone formation, atherosclerosis, and coronary artery disease [37]. The increase in the level of serum TC in G2 supplied with DZN may be due to an increased synthesis of cholesterol in the liver [38]. The present study is in agreement with Adham et al. [39] who reported that DZN causes an increase of TC and total lipid levels. The increase in serum cholesterol can be attributed to the effect of pesticides on the permeability of liver cell membrane [3]. Also, the increase in serum TC level may be attributed to the blockage of liver bile ducts causing reduction or cessation of its secretion to the duodenum [40]. Furthermore, in the present study, single dose of DZN $(300 \mathrm{mg} / \mathrm{Kg}$ ) caused significant increase in the serum levels of TG may be attributed to an inhibition of the lipase enzyme activity of both the hepatic triglyceride and plasma lipoproteins [41]. The present study is in agreement with Buyukokuroglu et al. (42) they demonstrated an increase in the serum triglyceride concentrations in the experimental animals that were treated with different insecticides, including the organophosphate, dichlorvos and carbamate furadan.

DZN treatment is found to elevate urea and uric acid levels in serum. Urea and uric acid are end products of protein metabolism that need to be excreted by the kidney, therefore, a significant increase of these parameters, as observed in this study in DZN group, provides an indication of functional damage to the kidney [43]. These observations are generally in agreement with other investigators on pesticides induction of relative effects [30,32]. Elevated serum urea is also correlated with an increased protein catabolism in mammalian body or more formation and efficient conversion of ammonia to urea as a result of increased synthesis of enzyme involved in urea production [44]. Pesticides induced an increase in urea level observed in the present study may be due to the effect of pesticides on liver function, as urea is the end product of protein catabolism [45].

Calcium is of a great importance in blood coagulation and as regulator of permeability of cell membrane to water and inorganic ions. It also contributes to the maintenance of the membrane potential as well as the development of action potential in muscles and nerves. A significant increase in serum calcium of rats supplied with $\mathrm{LD}_{50}$ of DZN was observed in G2. This may be due to release of calcium ions into the blood from vital organs due to toxic effect of the insecticides and renal damage and dysfunction occurred by insecticides which in turn impaired the ability of rats to actively excrete excess of these ions through kidney as reported by Logaswamy et al. [46]. Increased serum calcium levels have been reported in L. rohita, H. fossilis and M. vittatus, exposed to insecticides [47]. However, Swarnlata [48] reported raised level of serum calcium along with its decreased concentration in liver, muscle, brain and kidney of C. batrachus exposed to $2.03 \mathrm{ppm}$ and 0.24 ppm of carbaryl and carbofuran, respectively, for 15 days.

\section{Conclusion}

This study proved that supplementations of PM can reduce both the toxicity and oxidative stress of DZN treatment and that indicated by improve brain GSH, liver MAD, TP, Glob, TC, urea, uric acid and Ca levels to reach near normal control in G4 which supplemented with DZN+PM. This may be due to protective effects of PM on the damage induced by DZN. The present data showed that a high dose of DZN caused hematological and biochemical changes and the antioxidants PM ameliorated most changes studied here in.

\section{References}

[1]. T. S. S. Dikshith and P.V. Diwan, Industrial guide to chemical and drug safety (A Wiley-IEEE, 2003)

[2]. R.D. Johnson and D.D.Manske, Pesticide and other chemical residues in total diet samples, Pestic. Monit. J,11, 1977, 116-131.

[3]. G.W. Ware, The pesticide book (Fresno, CA., Thomson Publications, 2000). 
[4]. S. Kalender, A. Ogutcu, M. Uzunhisarcikli, F. Açikgoz, D. Durak, Y. Ulusoy, and Y. Kalender, Effects of diazinon on pseudocholinesterase activity and haematological indices in rats: the protective role of vitamin E, Environ Toxicol Pharmacol, $22,2006,46-51$.

[5]. S. Kalender, A. Ogutcu, M. Uzunhisarcikli, F. Açikgoz, D. Durak, Y. Ulusoy, Y. Kalender, DZN-induced hepatotoxicity and protective effect of vitamin E on some biochemical indices and ultrastructural changes, Toxicology, 211, 2005, $197-206$.

[6]. Y. Sharma, S. Bashir, M. Irshad, S.D. Gupta and T.D. Dogra, Effects of acute dimethoate administration on antioxidant status of liver and brain of experimental rats, Toxicol, 206, 2005,49-57

[7]. B. Ajaikumar, M. Asheef, B.H. Babu and J. Padikkala, The inhibition ofgastric mucosal injury by Punica granatum L. (pomegranate) methanolic extract, J Ethnopharmacol, 96, 2005, 171-176.

[8]. F. Afaq, M. Saleem, C.G. Krueger, J.D. Reed and H. Mukhtar, Anthocyanin- and hydrolyzable tannin-rich pomegranate fruit extract modulates MAPK and NF-kappaB pathways and inhibits skin tumorigenesis in CD-1 mice, Int J Cancer, 113, 2005, 423433.

[9]. E.P. Lansky and R. A.Newman, Punica granatum (pomegranate) and its potential for prevention and treatment of inflammation and cancer. J Ethnopharmacol,109, 2007; 177-206.

[10]. M.Turk, M. Sonmez, A. Aydin, S. Yuce, M. Gur, E.H. Yuksel, H. Aksu and H. Aksoy, Effects of pomegranate juice consumption on sperm quality, spermatogenic cell density, antioxidant activity and testosterone level in male rats, Clin Nutr, 27, 2008, 289-296.

[11]. V. M. Adhami and H. Mukhtar, Anti-oxidants from green tea and pomegranate for chemoprevention of prostate cancer, Mol. Biotechnol., 37, 2007, 52-57.

[12]. M. Aviram and L. Dornfeld, Pomegranate juice consumption inhibits serum angiotensin converting enzyme activity and reduces systolic blood pressure, Atherosclerosis, 158, 2001, 195-198.

[13]. N. P. Seeram, L.S. Adams, S.M. Henning, Y. Niu, Y. Zhang, M.G. Nair and D. Heber, In vitro antiproliferative, apoptotic and antioxidant activities of punicalagin, ellagic acid and a total pomegranate tannin extract are enhanced in combination with other polyphenols as found in pomegranate juice, J. Nutr. Biochem., 16, 2005, 360-367.

[14]. L.S. Adams, N.P. Seeram, B.B. Aggarwal, Y.S. Takada and D.Heber, Pomegranate juice, total pomegranate ellagitannins, and punicalagin suppress inflammatory cell signaling in colon cancer cells, J. Agric. Food Chem., 54, 2006, 980-985.

[15]. M.S.A. AL-Shinnawy, Effects Of Orally Fed DZN On SomeBiochemical Parameters Of Male Albino Rats, The Egyptian Journal of Hospital Medicine, 33, 2008, 559-568.

[16]. E. Beutler, O. Duron and M.B. Kelly, Improved method for the determination of blood glutathione, J Lab Clin Med 61, 1963, $882-888$.

[17]. H. Ohkawa, W. Ohishi and K. Yagi, Assay for lipid peroxides in animal tissues by thiobarbituric acid reaction, Anal Biochem, 95, 1979, 351 .

[18]. D. Agrawal, P. Sultana and G.S. Gupta, Oxidative damage and changes in the glutathione redox system in erythrocytes from rats treated with hexachlorocyclohexane, Food Chem Toxicol, 29, 1991, 459-462.

[19]. J.D. Hayes, J.U. Flanag and I.R. Jowsey, Glutathione transferases, Annu Rev Pharmacol Toxicol, 45, 2005 , 51-88.

[20]. N.S. El-Shenawy, F. El-Salmy, R.A. Al-Eisa and B. El-Ahmary, Amelioratory effect of vitamin E on organophosphorus insecticide diazinon-induced oxidative stress in mice liver, Pesti Biolo Physio. , 96, 2010,101-107

[21]. I. Camkayali, K. Demirag, O. Eris, B. Ersoz and A.R. Moral, The effect of N-acetylcysteine on oxidative stress in organophosphate poisoning model, Adv Ther, 22, 2005,107-116.

[22]. G. Kaur, Z. Jabbar, M. Athar and S. Alam, Punica granatum (pomegranate) flower extract possesses potent antioxidant activity and abrogates Fe-NTA induced hepatoxicity in mice, Food and Chemi Toxicol , 44, 2006, 984 - 993.

[23]. M. Cekmen, A. Otunctemur, E. Ozbek, S.S. Cakir, M. Dursun, E.C. Polat, A. Somay and N. Ozbay, Pomegranate extract attenuates gentamicin-induced nephrotoxicity in rats by reducing oxidative stress., Ren Fail, 35, 2013,268-74.

[24]. S.M. Mahmoud and A.E. Abdel Moneim,The Protective Effect of Pomegranate (Punica granatum) Juice against Carbon Tetrachloride-Induced Oxidative Stress in Brain Tissue of Adult Male Albino Rats, Life Sci J,10, 2013.

[25]. F. Visioli, C.A. de La Lastra, C. Andres-Lacueva, M. Aviram, C. Calhau, A. Cassano et al., Polyphenols and Human Health: A Prospectus, Criti Revie in Food Scien and Nutrit ,51, 2011, 524-546.

[26]. G. L. Robertson, and C.M.L. Samaniego, Effect of initial dissolved oxygen levels on the degradation of ascorbic acid and the and the browning of lemon juice during storage, Journal of Food Science, 51(1), 1986, $184-187$.

[27]. M. Namiki and T.Hayashi, A new mechanism of the Maillard reaction involving sugar fragmentation and free radical formation, in The Maillard Reaction in Foods and Nutrition, Ed by Waller GR and Feather MS. American Chemical Society, (Washington DC, USA, 1983) 21-47.

[28]. G. Ray. Pollution and health. (Wiley Eastern Ltd. New-Delhi, 1992) 45.

[29]. A.M. Al- Attar and W.A. Al-Taisan, Preventive Effects of Black Seed (Nigella Sativa) Extract on Sprague Dawley Rats Exposed to Diazinon, J of Basic and Appli Scien, 4, 2010, 957-968.

[30]. A.R. Shakoori, F. Aziz, J. Alam and S.S. Ali, Toxic effects of Talstar, a new synthetic pyrethroid, on blood and liver of rabbit. Pak. J. Zool., 22,1990, 289- 300.

[31]. A.P. Jyostana, J.P. Arun and P.G,Sanjay, Biochemical effects of various on sprayers of grape gardens, Indi.J.Clin.Biochem, 18, 2003, 16-22.

[32]. M.I. Yousef, F.M. El-Demerdash, K.I. Kamel and K.S. Al Salhen, Chages in some hematological and biochemical indices of rabbits induced by isoflavones and cypermethrin, Toxicol ., 189, 2003,223-234.

[33]. M. Rosenblat, T. Hayek and M. Aviram, Anti-oxidative effects of pomegranate juice (PJ) consumption by diabetic patients on serum and on macrophages, Atherosclerosis; 187(2), 2006, 363-71.

[34]. P. Saxena, K. Ashok and A.K. Saxena, Cypermethrin Induced Biochemical Alterations in the Blood of Albino Rats, Jordan J Biolo Scie ,3, 2010, $111-114$.

[35]. A.Diab, E.A., Abd El-Aziz, A.A. Hendawy, and R.Z. Hamza, Possible Ameliorative Role of Propolis and Ginseng against Hepatotoxicity of Chlorpyrifos and Profenofos in Male Rats. Journal of American Science. 8(8), 2012,

[36]. M.A.A. Mousa, A.M.M. EL-ashram and M. Hamed, Effect of neem leaf extract on freshwater fishes and zooplankton community.8th International Symposium on Tilapia in Aquaculture, 2008, 307.

[37]. D.W. Moss, A.P. Henderson and J.F. Kachmar, Enzymes in Fundamentals of Clinical Chemistry (N. W. (ed.), 3rd ed. WB Saunders Company. Philadelphia, USA, 1987).

[38]. E. Enan, I.G. Berberian, S. El-fiky, M. El-Masry and O.H. Enan, Effects of two organophosphorus insecticides on some biochemical constituent in the nervous system and liver of rabbits, J Environ Sci Health, 22, 1987,149-70. 
[39]. K.G.Adham, A. Khairalla, M. Abu-Shabana, N. Abdel- Mguid, and A. Abd El-Moneim, Environmental stress in Lake Maryut and physiological response of Tilipia Zilli Gerv, J. Environ. Sci. Health., 32, 1997, 2585-98.

[40]. L. Aldana, E.G.de Mejía, A. Craigmill, V. Tsutsumi, J. Armendariz-Borunda, A. Panduro and A.R. Rincón, Cypermethrin increases apo A-1 and apo B mRNA but not hyperlipidemia in rats, Toxicol. Lett., 95(1),1998,31-9 .

[41]. I.J. Goldberg, J.R. Paterniti, H.N. Ginsberg, F.T. Lindgren and W.V.Brown, Lipoprotein metabolism during acute inhibition of hepatic triglyceride lipase in the Cynomolgus monkey, J. Clin. Invest.,70, 1982, 1184-92.

[42]. M.E. Buyukokuroglu, M. Cemek, Y. Yurumez, Y. Yavuz and A. Aslan, Antioxidative role of melatonin in organophosphate toxicity in rats, Toxicol Letters, 172, 2007, 208.

[43]. N.C. Panda, Kidney. In: Textbook of Biochem- istry and Human biology (2ed., Prentise hall India, 1999) 290

[44]. R.K. Murray, D.K. Granner, P.A. Mayes and V.W. Rodwell, Harpers Biochemistry 22nd Edition, Lange Medical publication, 1990 .

[45]. E.H.Coles, Veterinary Clinical Pathology (W.B.Saunders,Philadelphia,USA,1986).

[46]. S. Logaswamy, G. Radha, S. Subhashini and K. Logankumar, Alterations in the Levels of Ions in Blood and Liver of Freshwater Fish, Cyprinus carpio var. communis Exposed to Dimethoate, Environ Monit Assess ,131, 2007, 439-444.

[47]. S.K. Bansal, S.R. Verma, A.K. Gupta and R.C. Dalela, Physiological dysfunction of the haemopoietic system in a freshwater teleost, Labeo rohita following chronic chlordane exposure. Part II. Alterations in certain organic compounds and serum electrolytes, Bull. Environ. Contam. Toxicol., 22, 1979,674-680.

[48]. T.A. Swarnlata, Toxicity and fate of carbamate pesticides on blood constituents of a freshwater fish, Clarias batrachus (LINN). Ph.D. Thesis, Avadh University; 1995. 